\title{
Review: daily maintenance inhaled corticosteroids are not effective for children with episodic viral wheeze
}

McKean M, Ducharme F. Inhaled steroids for episodic viral wheeze of childhood. (Cochrane Review, latest version 26 Oct 1999). In: Cochrane Library. Oxford: Update Software.

QUESTION: Are inhaled corticosteroids, given episodically or daily, effective for treatment of children with viral episodic wheeze?

\section{Data sources}

Published and unpublished randomised controlled trials were identified in April 1999 by searching the Cochrane Airways Group database (which includes studies identified from searches of Medline, EMBASE/ Excerpta Medica, CINAHL, and hand searches of 16 core respiratory journals and the proceedings of 3 respiratory societies) using combinations of the terms asthma, wheez* (truncated), budesonide, pulmicort, beclomethasone, becotide, fluticasone, flixotide, triamcinolone, steroid, corticosteroid, glucocorticoid, inhaled, aerosolised, nebulised, child, infan*, pediatric, paediatric, and adolescen*; bibliographies of retrieved trials; and contacting authors.

\section{Study selection}

Studies were included if they involved children aged $0-17$ years with viral episodic wheeze (defined as $\geqslant 2$ episodes of wheezing associated with clinical viral infection with minimal or no symptoms between exacerbations). Studies of children with classical chronic asthma (ie, wheezing episodes caused by stimuli other than viruses) or chronic lung disease were excluded.

\section{Data extraction}

Data were extracted on study design and methods, characteristics of participants, interventions, and outcomes (main outcome was episodes requiring oral corticosteroids). Study quality was independently assessed by 2 reviewers using the Jadad score.

\section{Main results}

5 studies were included in the analysis: 3 studies examined episodic high dose inhaled steroids $(n=122)$ and 2 examined low dose, daily maintenance inhaled corticosteroids $(\mathrm{n}=161)$. Episodic corticosteroids, compared with placebo, reduced exacerbations requiring emergency department visits $(1$ study, $\mathrm{n}=52)($ table $)$ and were associated with higher parent preferences (2 studies, $\mathrm{n}=120$ ) (table); no group differences were found for exacerbations requiring oral steroids or hospital admission, severity of lower respiratory tract (LRT) symptoms, or sleep disturbance. Daily maintenance corticosteroids, compared with placebo, did not reduce exacerbations requiring oral steroids, emergency department visits, or hospital admissions; duration and severity of episodes with LRT symptoms; frequency of wheezing episodes; frequency, severity, and duration of PEF reductions; and $\mathrm{FEV}_{1}$ changes.

\section{Conclusion}

Among children with episodic viral wheeze, episodic treatment with inhaled corticosteroids reduces exacerbations requiring emergency department visits and is preferred by parents; daily maintenance treatment does not improve any outcomes.

Episodic inhaled corticosteroids v placebo for episodic viral wheeze in children*

\begin{tabular}{lllll} 
Outcomes at $\leqslant 4$ months & $\begin{array}{c}\text { Episodic } \\
\text { steroids }\end{array}$ & Placebo & RRR (95\% CI) & NNT (CI) \\
$\begin{array}{c}\text { Exacerbations requiring } \\
\text { emergency department visit }\end{array}$ & $62 \%$ & $89 \%$ & $30 \%(3$ to 50$)$ & 4 (2 to 22$)$ \\
\hline & & & RBI (CI) & NNT (CI) \\
\hline Parent preferred treatment & $75 \%$ & $48 \%$ & $55 \%(15$ to 109$)$ & 4 (3 to 10$)$ \\
\hline
\end{tabular}

*Abbreviations defined in glossary; RRR, RBI, NNT, and Cl calculated from data in article.

\section{COMMENTARY}

Among children $<5$ years of age, the most common cause of asthma symptoms is viral upper respiratory infection. ${ }^{1}$ Many children become symptomatic with wheezing before the age of 2 years. ${ }^{2}$ Some will develop asthma; others will not. How should we treat these young children who may or may not have asthma? McKean and Ducharme focused their systematic review on whether episodic or daily maintenance inhaled corticosteroids are effective for viral episodic wheeze in children. It is a noteworthy question as the US National Asthma Education and Prevention Program ${ }^{1}$ and the more recent American Academy of Allergy, Asthma, and Immunology are cautious about the use of inhaled steroids, despite evidence of their general usefulness and safety ${ }^{4}$ for these wheezing children who may or may not have asthma.

Primary care nurses face the challenge of treating essentially well young children who wheeze with upper respiratory infections. The evidence from the 5 European studies included in this systematic review provide preliminary evidence of the usefulness of episodic inhaled corticosteroids in children as young as 7 months of age. The studies, however, varied in the type, dose, and delivery of inhaled corticosteroids, and no attempt was made to stratify children with atopic wheeze from those with non-allergic wheeze to uncover whether different disease processes were at work. Also, the generalisability of the positive findings of parent preference and a reduction in emergency department visits is unclear, as countries outside of Europe may have very different healthcare systems. For example, in the US, national guidelines do not promote inhaled corticosteroids for even mild intermittent asthma, ${ }^{3}$ and, until July 2000, no inhaled corticosteroid had been labelled for use in children younger than 4 years of age.

Gene Elizabeth Harkless, RN, DNSc, ARNP Associate Professor/Family Nurse Practitioner Department of Nursing, University of New Hampshire Durham, New Hampshire, USA

1 National Asthma Education and Prevention Program Expert Panel Report 2: guidelines for the diagnosis and management of asthma. Bethesda, MD: National Heart, Lung, and Blood Institute, 1997.

2 Szefler SJ. Clinical need for a nebulized corticosteroid. J Allergy Clin Immunol 1999;104:162-8.

3 American Academy of Allergy, Asthma, and Immunology. Pediatric asthma: promoting best practice guidelines for managing asthma in children. Milwaukee, Wisconsin: American Academy of Allergy, Asthma, and Immunology, 2000.

4 Bisgaard H. Use of inhaled corticosteroids in pediatric asthma. Pediatr Pulmonol Suppl 1997;15:27-33. 